Кипчаков Б.Б. доиент,

Дусанов У.С. дочент,

Тоимуродов $О . Э$. доиент

Самаркандский государственный университет

\title{
OUTDOOR GAMES AND THEIR USE IN SPORTS PRACTICE
}

\section{АННОТАЦИЯ}

DOI: $\underline{10.31618 / E S U .2413-9335.2020 .3 .75 .839}$

В статье представлены материалы по специально-методическому анализу и обобщению подвижных игр: позволяющие развивать не только двигательные качества, но и оценивать ЧСС, дыхательную и другие системы организма, захватывать эмоциями, снимать утомление, вялость и удовлетворять все двигательные потребности молодого организма юных спортсменов.

\section{ABSTRACT}

The article presents materials on a special methodological analysis and generalization of outdoor games: it sheds light on not only developing movement qualities, but also assesses heart rate, respiratory and other systems of the body, capturing emotions, relieve fatigue and satisfying all the motor needs of the body of young athletes are also considered.

Ключевые слова: Подвижные игры, развитие двигательных качеств, оценка ЧСС, Дыхательные системы, утомляемость, юные спортсмены

Keywords: Outdoor games, development of movement qualities, heart rate assessment, respiratory system, fatigue, young athletes.

Актуальность. Подвижное игры с элементами по видом спорта единоборцев близких к ролевой игре и элементами отдельных видов спорта, каторая занимает одно из главный мест в деятельности юных спортсменов борьбе-кураш. Все это обеспечивает значительно больше время участия юных спортсменов в данных видах игровой деятельности, чем при обычных подвижных играх.

Из наблюдений известно, что немало учащихся свободное время проводят насыщенно и интересно, благодаря активному и умелому участию в играх, эстафетах, спортивно-массовых мероприятиях, а также викторинах и аттракционах. Регулярное участие в соревнованиях по подвижным играм позволяет им избегать различных заболеваний, становиться усидчивее и внимательнее в учебе и труде, по сравнению с их менее активными сверстниками. Следовательно, подвижные игры имеют большое оздоровительное и гигиеническое значения и по сравнению с другими видами игр имеют немалые преимущества.

Они улучшают сердечно - сосудистую, дыхательную и другие системы организма, стимулируют обмен веществ и деятельность желез внутренней секреции. Подвижные игры с их динамизмом захватывающими эмоциями снимают утомление, вялость и удовлетворяют все двигательные потребности молодого организма.

Особенность подвижных игр естественным образом снимать усталость вполне соответствует характеру и двигательным потребностям учащихся. Еще одна особенность подвижных игр состоит в том, что даже очень слабый, малоактивный и стеснительный постепенно втянется в игру. Подвижность и боевой задор в игре даже слабого заставляет не отставать от других, и очень скоро он начинает ощущать себя полноценным игроком. Наконец, весьма полезным свойством подвижных игр можно считать то, что в процессе игры учащиеся хорошо узнают друг друга, привыкают подчиняться правилам, учатся терпению и взаимопомощи. Главное, они развивают в себе готовность не желать сил для победы своей команды, не оставлять в трудной ситуации своих партнеров.

Что же надо сделать, чтобы подобрать соответствующую общим интересам игру овладеть соответствующими навыками?

Прежде всего ознакомьтесь с условиями и правилами ряда игр, и выберите то из них, которые будут вам и интересны и полезны.

\section{«Сохрани платочек»}

Описание игры.

В кругу находится водящий с платочком за поясом. За кругом стоят несколько игроков. Задача каждого из них - вытянуть платочек у водящего, делая только один шаг внутри круга. Задача водящего не дать игрокам это сделать. Игрок, который вытянет платочек, становится водящим, а прежний водящий выбывает из игры (рис. 116).

\section{Правила игры.}

Водящему нельзя выходит за пределы круга. Игрокам запрещается второй ногой заступать в круг. За кругом могут находиться от двух до семи игроков. В кругу могут находиться двое водящих. 


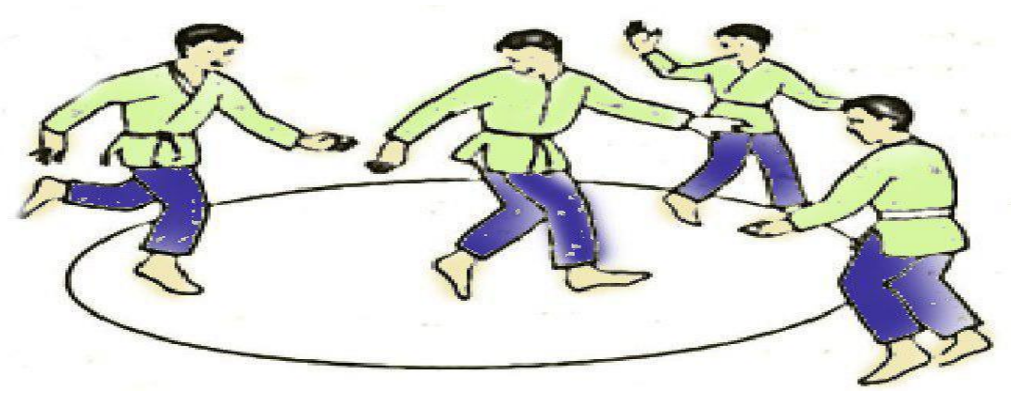

(puc. 116).

Описание игры.

«Самый ловкий»

Игроки делятся попарно, принимают исходное положение - стойку на коленях. По сигналу каждый начинает касаться плеча другого ладонью.
Задача как можно больше раз коснуться плеча соперника. Побеждает тот, кто выполнит наибольшее число касаний за один минуту (рис. 117).

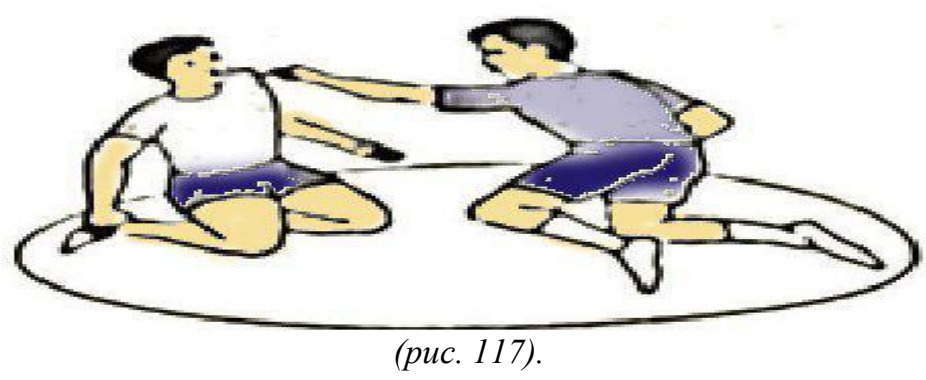

Правила игры.

Игроки должны лишь слегка дотрагиваться ладонью до обозначенной части тела соперника. Запрещается наносить сильные болевые удары.

Можно играть касанием головы, колена.

Можно играть стоя во весь рост, касаясь различных частей тела.

\section{«Ладушки»}

Описание игры.

Два игрока выходят в круг диаметров 3м, становятся в стойку. Задача каждого выполнить побольше хлопков под коленом соперника и не дать ему возможности произвести те же действии. Партнер, успевший выполнить за время игры хлопков больше соперника, считается победителем.
Правила игры.

Игрокам запрещается выполнять захваты и выходить за проделы круга. Разрешается выполнять хлопок только на заранее обусловленной ноге.

Хлопок можно выполнять под коленом любой ноги.

Описание игры.

$$
\text { «Лошадки» }
$$

Играющие встают спиной друг к другу, на них надевают через шею толстую лямку, которая должна пройти у них подмышками и плотно обтянуть их грудь. По сигналу каждый участник поединка старается перетянуть своего партнера в свою сторону за черту (рис. 118).

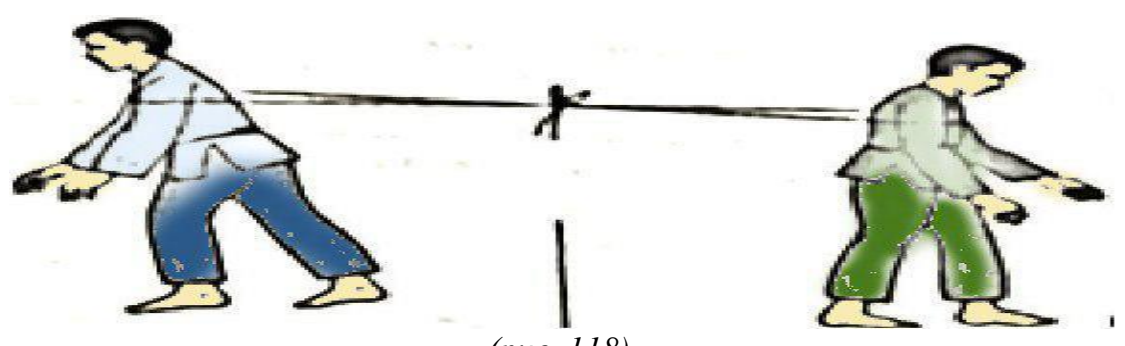

Правила игры.

(puc. 118).
Если играющие не сумеют выполнить эту задачу в течение 30 секунд, поединок заканчивается вничью.

Можно играть попарно.

Соревнование можно проводить между командами.

\section{«Кто сильнее?»}

Описание игры.
Участники находятся в упоре лежа, держась за одноименные руки (захват за запястье). Задача игроков- перетянуть соперника в свою сторону, заставить его потерять равновесие. Выигрывает тот, кто первым осуществит поставленную задачу (рис. 119).

Правила игры.

Не разрешается вставать на колени.

Игру можно проводить в исходном положении на четвереньках. 
Можно играть, выполняя захват за запястья соперника правой или левой рукой.

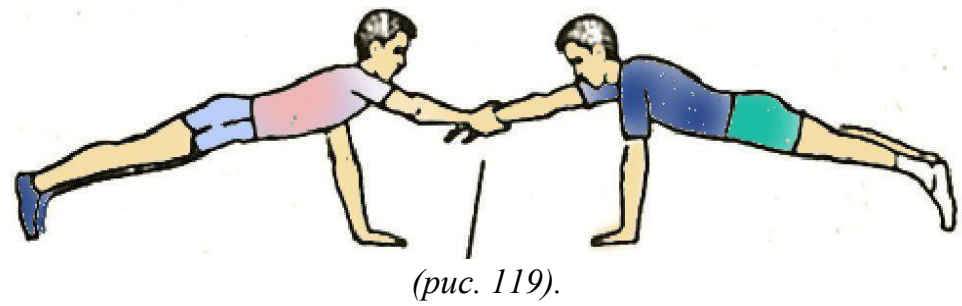

Описание игры.

«Выталкивание спиной»

Игроки садится спиной друг к другу и выполняют захват под руки. Задача каждого игрока, упираясь спиной, вытолкнуть соперника за пределы круга (рис. 120).

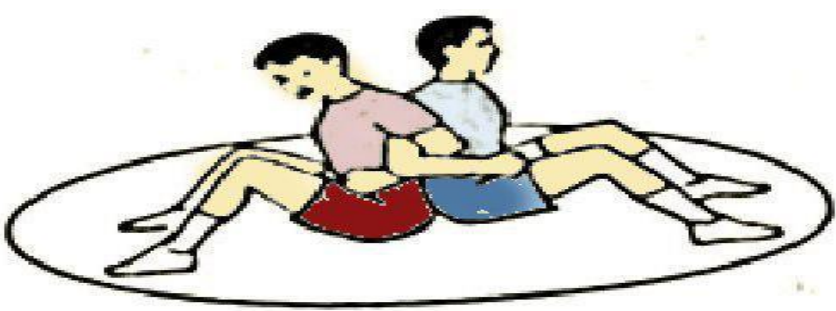

(puc. 120).

Правила игры.

Нельзя отрывать ноги от ковра, а также разрывать захват рук.

Можно разрешить игрокам подниматься из положение стоя. Можно бороться стоя; победителем остановится тот игрок, который вытолкнет соперника из круга.

Описание игры.

\section{«Выручай»}

На противоположных сторонах площадки проводятся параллельные линии. Все играющие становятся на одной стороне площадки. В центре площадки обозначаются маленькие круги. В каждом кругу стоят по два ловца.

Игра начинается по сигналу учителя. Он произносит: «Раз, два, три, беги!», после этого все учащиеся стремятся добежать и пересечь линию на противоположной стороне.

Игроки-ловцы, стоящие в кругах, выскакивают из них и стараются поймать перебегающих игроков.

Игрок, которого коснулся ловец, сам становится в круг. При обратном пробегании играющие могут выручить пойманных, коснувшись их рукой. Игру можно повторить 3-4 раза.

Правила игры.

Бежать разрешается только после команды учителя «Беги!».

Если ловцы касаются выручающих, то и они идут в круг и они идут в круги находятся там, пока их но выручат другие.

Описание игры.

Для игры нужна веревочка длиной 3-4 м, на конце которой привязан мешочек с песком. Иногда для игры используют обычную скакалку. Это удочка, с помощью которой рыбак (водящий) ловит рыбок.
Все играющие становятся в середине круга с веревкой в руках. Он вращает веревочку с мешочком так, чтобы тот скользил по полу, делая круг за кругом под ногами играющих. Они внимательно следят за движением мешочка, подпрыгивают, чтобы не быть задетыми. Тот, кого заденет мешочек или веревка, становится в середину и начинает вращать веревку, а бывший водящий идет в круг.

Правила игры.

Пойманным игрок считается в том случае, если веревочка коснулась его ноги не выше голени.

Не разрешается во время прыжков приближаться к водящему.

Задевший веревку выбывает из игры;

Выигрывают 2-3 игрока, оставшиеся последними.

\section{«Борьба за мяч»}

Описание игры.

Участники располагаются, сидя на полу спиной друг к другу и к лежащему мячу. По сигналу руководителя игроки должны схватить мяч. Тот, кто первым им завладеет, считается победителем.

Правила игры.

Игрок, намеренно столкнувшийся с соперником, считается проигравшим.

Игру можно проводить стоя.

Можно уменьшить размеры мяча, усложняя тем самым игру.

Описание игры.

\section{«Быстрее перетяни»}

Игроки располагаются спиной друг к другу. По сигналу руководителя они стараются схватить веревку, которая лежит под ногами обоих игроков. Тот, кто первым ее схватит, считается победителем.

Правила игры. рукой. 
Игроков можно расположить друг к другу. Игру можно проводить сидя на полу или на стуле.

$$
\text { «Тяни в круг» }
$$

Описание игры.

Игроки встают с внешней стороны круга, крепко держась за руки. По сигналу они двигаются вправо или влево, затем по второму сигналу останавливаются и стараются втянуть внутрь круга ближайших партнеров, не разъединяя рук.

Правила игры.

Игрок, заступивший во внутрь круга хотя бы одной ногой, выходит из игры. Затем игра продолжается. Игроки, оставшиеся в игре после нескольких туров, считаются победителями. Игрокам не разрешается разъединять руки в процессе игры.

\section{Литература:}

1. Болеева Л.В, Коротков И.М Подвижные игры м:срис. 1085.1920.

2. Яковлев В.Г, Ратников В.П Подвижные игры М:Просвешение. 1977

3. Усманходжаев Т.С и др Миллий ва харакатли уйинлар Т “Iqtisod moliv" 2015

\title{
ПЕДАГОГИЧЕСКИЕ АСПЕКТЫ ФИЗИЧЕСКОГО СОВЕРШЕНСТВОВАНИЯ ДЕТЕЙ И МОЛОДЁЖИ В СВЯЗИ С ИХ ДВИГАТЕЛЬНОЙ АКТИВНОСТИ.
}

\author{
Усманхужаев T.C. \\ (д.n.н., профессор) \\ Государственный институт физической культуры и спорта Узбекистана \\ ДусановУ.С. \\ (к.и.н., доиент) \\ Самаркандский государственный университет
}

\section{PEDAGOGICAL ASPECTS OF PHYSICAL IMPROVEMENT OF CHILDREN AND YOUTH IN CONNECTION WITH THEIR MOTOR ACTIVITY}

\section{АННОТАЦИЯ}

DOI: $10.31618 /$ ESU.2413-9335.2020.3.75.845

В статье рассматривается рациональная научность применения ценностей физической культуры для совершенствования физических и духовно-нравственных характеристик в современных условиях.

\section{ANNOTATION}

The article sheds light on the rational scientific nature of the application of the values of physical culture to enhance physical and spiritual-moral characteristics in modern conditions.

Ключевые слова: Физкультурные занятия, моторная плотность, последовательность и объём физических упражнений, потребность человека, климатические ситуации, экологические обстановки, национальные и культурные традиции.

Keywords: Physical training, motor density, sequence and volume of physical exercises, human need, climate situation, environmental situation, national and cultural traditions.

Актуальность Детей во взаимосвязи с их двигательной активностью требует комплексного решения в контексте возрастных, медикогигиенических, биологических, социальных, демографических, климатических, географических, бытовых и других факторов. В методике определения двигательной активности в данном комплексе должны быть приняты во внимание не только ее количественные показатели, но и качественные: оббьем, характер оргонизованных форм физкультурных занятий, их моторная плотность, последовательность и объём физических упражнений, необходимых для повышения физической подготовленности детей и подростков. Немаловажное значение в этом вопросе играет создание условий в семье, способствующих выполнению детьми заданий по физическому воспитанию в целях приобщения их к самостоятельным занятиям физической культурой.

Кроме того, анализ современных исследований по проблеме двигательной

Физическое совершенство как один из существенных аспектов всестороннего развития человека представляет собой исторически сложившийся оптимальный уровень здоровья и физических способностей соответствующий требованиям человеческой жизнедеятельности в ее различных формах проявления как в сфере личностного, так и общественного бытия и обеспечивающий на долгие годы высокую активность и работоспособность. При этом физическое совершенство может быть подлинным лишь в контексте высоко духовного облика данной личности, т.е. при условии органического единства физических и духовных сил, сочетания физического и духовно нравственного совершенства. Физическое совершенство - это оптимальная мера обшей физической подготовленности, согласующая с закономерностями всестороннего развития личности и долголетнего сохранения крепкого здоровья.

На наш взгляд, одно из важнейших закономерностей формирования физического совершенства выступает необходимость реализации этого процесса с рождения человека и продолжения на всех остальных этапах его жизнедеятельности. При этом, одним из наиболее ответственных и по существу решающих этапов физического совершенствования человека, является детский возраст, на которой приходится пик его двигательной активности, высокие 